\title{
SOME ASPECTS OF RECENT RESEARCHES ON FEEDING DAIRY GOATS
}

\author{
A.E. Kholif \\ Dairy Science Department, National Research Centre, 33 Bohouth St. Dokki, Giza, Egypt \\ E-mail: ae_kholif@live.com ae.kholif@nrc.sci.eg
}

Received: 2/8/2019 Accepted: 13/10/2019

\section{SUMMARY}

Much research is being conducted to improve the performance and the quality of fatty acids (FA's) in goat milk with regard to effects on human health. During early lactation and peak production, lactating goats can mobilize considerable body fat for support of milk production, but this can necessitate a high nutritional plane later for replenishment. The levels of dietary concentrate and forage, quality of forage, and production system have great effects on body weight $(B W)$ gain, milk production and milk composition of goats. Opportunities for enhancing the performance ( $B W$ gain and milk) of goat with high concentrate levels are greater in early than late lactation; however, the efficiency of energy use in late lactation is greater when tissue is often replenished. Regionally available by-products and other nonconventional feedstuffs can be used to minimize production costs. The efficiency of feeding by-products and alternative feedstuffs on ruminal methane emission, milk fat content and FA composition, and antioxidant status depends on major and minor constituents and what they are substituted for. The increasing concerns regarding the inclusion of synthetic antimicrobials in goat's diet have compelled nutritionists to explore minor dietary ingredients or additives such as probiotics and plant secondary metabolites to enhance the performance, although specific components responsible for effects are sometimes unclear. Such minor ingredients can influence bioactive ruminal biohydrogenation intermediates that decrease de novo FA synthesis in the mammary gland. Supplementing goats with sources of conjugated linoleic acid has been studied, but the use is not common probably because of marginal changes in milk fat content and FA composition compared with cattle. Some differences in the effects of dietary inclusion of fats and oils between dairy goats and cattle may relate to ruminal microbial conditions as well as the susceptibility of mammary gland enzymes to bioactive conjugated linoleic acid isomers. Inclusion of moderate dietary levels of oils and other fat sources for purposes such as increased energy density, improved palatability, and decreased dustiness are well documented.

Keywords: dairy goats, fatty acids, nutrition, performance

\section{INTRODUCTION}

In Egypt, there are many production systems for goat production including extensive, semi-intensive and smallholder. The extensive system prevails in the northwestern coastal zone and Sinai. This production system is characterized by long-distance movements to search for feed and natural pastures. The flocks in this system are usually large. In the semi-intensive production system, goats are reared in reclaimed areas representing the main source of income. The smallholder production system is prevailing in the Nile Valley and the Delta, where goats are kept in small flocks and are mainly reared for home consumption and to generate additional income. In 2019, the Food and Agriculture Organization (FAO) estimated the number of goats in Egypt to be 4,351,545 head.

The objective of this article is to review current research of the nutrition and feeding of dairy goats, considering the articles published by Goetsch (2016, 2019) and Mamuad et al. (2019) as guidelines. Recently, there are many topics that gained more interests from nutritionists regarding the nutrition and feeding of dairy goats. With no single area that can be easily justified as being much more important than others, the article will focus mainly on:

1) Dietary concentrate and fiber levels

2) By-product and alternative feedstuffs

3) Dietary additives and plant secondary metabolites

4) Dietary inclusion of fat and oil

\section{Dietary concentrate and fiber levels:}

Levels of concentrate versus forage or roughage in ruminant diets have been extensively studied throughout the years to reach the best ratios for different production types. However, the immense variability in the nature of feedstuffs within each class, interactions and associative effects between feeds, research in this general area will undoubtedly continue(Goetsch, 2016). Compared to dairy cows, the level of production by dairy goats is not improved or is increased relatively less by use of very high dietary levels of concentrate with no exact reasons for this (Goetsch et al., 2011). For example, mammary gland enzymes of goats have been reported to be less sensitive to inhibition than those of dairy cattle (Toral et al., 2015).The less intense selection of breeds of dairy goats versus cattle for milk yield, faster digesta flow through the 
gastrointestinal tract, and differences in susceptibility of mammary gland enzymes to influences of bioactive fatty acids (FA) biohydrogenation intermediates from the rumen are probable reasons (Goetsch, 2016). Differences in dietary concentrate and fiber levels greatly affect the performance of dairy goat (Serment et al., 2011). Moreover, the ratio of concentrate: forage plays an important role in feed utilization and animal performance. Increasing the ratio of concentrates enhances feed intake and animal performance. Serment et al. (2011) fed Saanen and Alpine does on diets 70 or $35 \%$ in concentrate from 95 to 165 days in milk (DIM), and observed low milk fat concentration for the high versus low concentrate diet. Feeding high concentrates can decrease biohydrogenation activity of ruminal microbes(Harfoot and Hazlewood, 1988), resulting in elevated mammary gland levels of biohydrogenation intermediates that lessen de novo FA synthesis. In another experiment, Giger-Reverdin et al.(2014) fed Alpine and Saanen goats on diet with 30 or $60 \%$ from 79 to 135 DIM, and observed greater feed intake for the high than low concentrate diet. They explained this effect by metabolic versus physical fill intake controls, although there were more off-feed periods with the high concentrate diet.

Feeding high concentrate diets requires greater attention to feeding management practices compared with ones higher in fiber due to probable subacute ruminal acidosis. Goats consume and digest high concentrate diet more rapidly than the low concentrate diet, with a shorter total eating time. Additionally, feeding goat on high concentrate dietled to a decreased ruminal $\mathrm{pH}$ and acetate, while propionates and ammonia concentrations were increased. A lower hematocrit level for the high than low concentrate diet was observed and can be explained by water flow from blood through the rumen wall to lessen the rise in osmotic pressure in the rumen (Serment et al., 2011).

The main issue in the concentrate and forage levels is the physically effective neutral detergent fiber (peNDF). The peNDF is more highly related to digestive function in ruminants than levels of forage or total NDF in the diet.Li et al. (2014) fed Xinong Saanen goats on a $51 \%$ concentrate diet with two levels of peNDF. A pH below 5.60 was much longer for the low than high peNDF diet; however, mean daily ruminal $\mathrm{pH}$ and milk yield and composition were similar. Moreover, the lower peNDF diet resulted in greater total VFA concentration in the rumen and decreased time spent in eating without affecting the ratios of acetate, propionate, or butyrate.

\section{By-product and alternative feedstuffs}

Due to cost and availability, the inclusion of byproduct and alternative feedstuffs replacing conventional feedstuffs gained a great interest; however, can markedly affect the nature of concentrate and forage and roughage fractions of the diet. Replacement of conventional feeds with by- products expected to affect ruminal fermentation and alter milk production and composition (Kholif et al., 2018; Abd El Tawab et al., 2020).

Razzaghi et al. (2015) replaced wheat bran with pomegranate seed pulp, pistachio hulls or tomato pomace in the diet of Saanen goats at 90 to 174 DIM, and reported similar intake, yields of total milk, fat, protein and lactose, and milk efficiency; however, increased conjugated linoleic acid (CLA) level for all by-product diets. Pomegranate seed pulp increased levels of total unsaturated FA's (UFA's) compared with the other diets.

Using date palm (Phoenix dactylifera L.) in feeding dairy goats has increasing interests. High quality date palm is an important human food, but date palm viewed unsuitable because of quality issues can be fed to dairy goats partially because of levels of compounds with antioxidant properties(Sharifi et al., 2015).Sharifi et al. (2015) replaced barley in 50\% concentrate diets of Saanen goats with low-quality date palms from 92 to 176 DIM at 6,12 , or $18 \%$ of the diet. They observed unchanged milk yield and intake; however, the levels 12 and $18 \%$ decreased the ratio of ruminal acetate to propionate. Interestingly, diets contained date palm showed greater total antioxidant capacity in blood and milk without affecting malondialdehyde levels in blood and milk.

Another by-product gained research interests is Moringa oleifera leaf meal (Kholif et al., 2015; Kholif et al., 2016; Kholif et al., 2018). In a study by Kholif et al. (2015) replaced sesame meal with $M$. Oleifera leaf meal at different levels in the diet of Anglo-Nubian goats as an unconventional protein feed. They observed increased feed intake, total milk and milk energy yields with leaf meal inclusion. $M$. oleifera leaf meal decreased saturated FA (SFA)and increased UFA and CLA concentrations, presumably because of differences in FA composition between leaf meal and sesame seed meal.

\section{Dietary additives and plant secondary metabolites:}

Dietary additives including probiotics, exogenous enzymes, yeast, etc. gained increasing interests as feed additives. The main reason for administration of bacteria-based probiotics in the diet of dairy goats is to achieve conditions in the gastrointestinal tract conducive to good health and high performance through increasing prevalence of beneficial microbes and decreasing that of potentially pathogenic ones. The potential benefits from administration of such products for lactating dairy goats would depend primarily on feeding practices such as dietary concentrate and peNDF levels.

Bacteria-based probiotics are marketed for use as a treatment for digestive disturbances as well as daily administration to enhance feed utilization and lactational performance (Abd El Tawab et al., 2020). Similarly, but with different mode of action, yeastbased probiotics are being used of particular interest with relatively high concentrate diets that cause low 
ruminal $\mathrm{pH}$, limit microbial diversity, and result in a relatively high propensity for digestive disturbance (Chaucheyras-Durand et al., 2012). Live yeast has been proposed to increase and stabilize ruminal $\mathrm{pH}$ by decreasing lactate production (ChaucheyrasDurand et al., 2012). Kholif et al. (2017) theorized that because of different general modes of action, effects of commercially available live yeast and exogenous enzyme products could be synergistic. Sixteen Nubian does with a BW of $35.1 \mathrm{~kg}$ were used in aquadruplicated $4 \times 4$ Latin square study with 22 day periods. Products were included in the $60 \%$ concentrate diet alone or together. Though effects were not synergistic, each product positively affected a large number of variables including DM intake, milk yield and fat concentration. Live yeast treatment increased feed intake, milk yield, energy corrected milk, milk component yields, and feed (milk) efficiency, as well as increased ruminal $\mathrm{pH}$, and concentrations of total and individual volatile fatty acids (VFA's). With responses to such products not always observed, research with longer feeding periods, other diets, and animals with greater BW, DM intake, and milk yield would be beneficial. In another experiment using a bacteria-based probiotic, Maragkoudakis et al. (2010)fed 24 Damascus females at about 3 to 4 months of lactation on diet supplemented with Lactobacillus planetarium obtained from cheese. Treatment increased the prevalence of lactic acid bacteria in feces and decreased clostridial bacteria.

Considerable research is being conducted with essential oils to decrease the use of synthetic antimicrobials (e.g. ionophores) aiming to modifying end products of ruminal microbial fermentation. Additionally, researches performed to evaluate their ability to decrease methane $\left(\mathrm{CH}_{4}\right)$ emission and enhance degradation of intact feed protein and increased antioxidant capacity of blood, tissues, and milk are essential. Paraskevakis (2015) reported that supplementing Alpine does at 120 to 148 DIM with $30 \mathrm{~g}$ of dried Greek oregano (supply1 $\mathrm{mL} / \mathrm{d}$ of essential oil with $91.5 \%$ carvacrol) increased levels of glutathione peroxidase and reductase in blood and milk and enhanced ferric reducing antioxidant power in milk. In another experiment, Miri et al. (2013) supplemented diets of Alpine $\times$ Beetal goats in early lactation with cumin (Cuminum cyminum) seed extract at $0,1.27$, and $2.53 \%$ of the diet, and observed increased milk yield by $13 \%$ and decreased ruminal $\mathrm{CH}_{4}$ emission by $14.2 \%$ relative to feed intake with the both levels. Additionally, the extract increased levels of several UFA's, including the CLA isomer rumenic acid. Morsy et al. (2018) supplemented the diet of Damascus goats with cumin seeds at $10 \mathrm{~g}$ daily and reported enhanced nutrient digestibility, ruminal total SCFA production, and molar proportion of propionate. Moreover, cumin seeds elevated milk production, milk contents of fat and lactose and lowered milk SFA and decreased total UFA and CLA contents. The positive effects of phytogenics on feed utilization and lactational performance of goats might be due to its contents of active components that have the ability to inhibit rumen microbial enzymes involved in biohydrogenation, and polyphenols present could affect different steps of ruminal biohydrogenation of FA as well(Goetsch, 2016; Goetsch, 2019). Additionally, some components of essential oils could increase small intestinal lipid absorption by increasing bile salt availability. Decreasing ruminal $\mathrm{CH}_{4}$ emission was thought a consequence of influences of phenols, saponins, or essential oils in decreasing $\mathrm{H}_{2}$ production by gram-positive bacteria and activity of ruminal protozoa often found in close association with methanogens. However, direct effects of polyphenols on activity of methanogens are also likely (Puchala et al., 2012a; Puchala et al., 2012b).

Bromochloromethane is a halogenated analog receiving attention as an inhibitor of terminal steps in ruminal methanogenesis (Abecia et al., 2012). Bromochloromethane is only an experimental model because of its ozone-depleting effect and thus noncommercial use (Abecia et al., 2012). Bromochloromethane has many advantages that may overcome most problems related to other $\mathrm{CH}_{4}$ inhibitors such as fats and oils at high levels of supplementation (Beauchemin et al., 2008). Abecia et al. (2012) observed a reduced ruminal $\mathrm{CH}_{4}$ emission of Murciano-Granadina goats in midlactation by $33 \%$ through the supplementation with bromochloromethane. Moreover, its supplementation was accompanied by increased milk yield and efficiency of production presumably because of a decreased ratio of acetate to propionate in ruminal fluid.

\section{Dietary inclusion of fat and oil:}

The inclusion of various sources of FA in the diet of dairy animals, particularly cattle compared to goat, gained more interest in the last few years. There are several species differences between cattle and goats that prevent direct extrapolation of findings with cattle to goats. The primary ones are greater de novo mammary gland synthesis of C8:0, C10:0, and C12:0 (Chilliard et al., 2003) and less desaturation of stearic to oleic acid in goats(Toral et al., 2015). Toral et al. (2015)compared Alpine dairy goats and Holstein cows consumed a $60 \%$ concentrate diet with or without inclusion of 50 or $120 \mathrm{~g} / \mathrm{d}$ of fish or sunflower oil, respectively (approximately 2.2 and $5.5 \%$ feed intake, respectively). The noted lesstrans10, cis-12 CLA isomer activity in goats compared with cattle.

The objectives of CLA supplementation is to affecttrans-10, cis-12 CLA in milk and to decrease milk energy yield and tissue mobilization in early lactation and improving energy balance. Baldin et al. (2014)fed Toggenburg goats from 75 to 111 DIM diets with approximately $63 \%$ concentrate that did or did not contain an unprotected CLA methyl ester supplement, consisting of $27 \%$ oleic acid, $30 \%$ rumenic acid, and $30 \%$ of the trans-10, cis-12 CLA 
isomer. Depressions in milk fat content and yield were 13.9 and $13.3 \%$, respectively, small comparedto the result of Lock et al. (2008)and Shingfield et al. (2008)which were 17.5 to $21 \%$. It was suggested that this might have resulted from animal factors such as a genetic difference in responsiveness to this CLA isomer. Moreover, there could be less potential for effects with primiparous than multiparous animals because of differences in possible milk yield and nutrient partitioning for continual growth and development of primiparous animals. Ghazal et al. (2012) supplement a $65 \%$ concentrate diet of Saanen and Alpine goats with a mixture of cis-9, trans-11 and trans-10, cis-12 isomers of C18:2 and Ca salts of palm oil. They reported that milk fat yield and content were decreased by 18 and $15 \%$, respectively. Moreover, additives reduced the synthesis of shortand medium-chain FA.

Some effects of dietary supplementation of goats with oils and various fat sources are similar to those derived from use of CLA products. Soybean oil is frequently used as a rich source of oleic and linoleic acids should be included in diets with caution so that negative effects on intake or digestion do not occur or are not severe. Kholif et al. (2016a) supplemented diet of Nubian goats with flaxseed oil or soybean oil (10 $\mathrm{mL}$ of soybean oil daily), ruminal $\mathrm{pH}$, and acetate were reduced while total VFA and molar proportion of propionate were increased. Oils supplementation increased milk yield, UFA, CLA, and the athrogenicity index of milk while milk-fat contents and SFA concentrations were decreased. Razzaghi et al. (2015b) noted similar effects on milk FA composition when supplementing Saanen goats consuming a $60 \%$ concentrate diet at 30 to 84 DIM with regular sunflower oil at $3.7 \%$ feed intake, without effect on milk fat or yield.

\section{REFERENCES}

Abd El Tawab, A.M., A. E. Kholif, A. M. Hassan, O. H. Matloup, S. A. Abo El-Nor, O. A. Olafadehan, and M. S. A. Khattab. 2020. Feed utilization and lactational performance of Friesian cows fed beet tops silage treated with lactic acid bacteria as a replacement for corn silage. Anim. Biotechnol. in press.

Abecia, L., P. G. Toral, A. I. Martín-García, G. Martínez, N. W. Tomkins, E. Molina-Alcaide, C. J. Newbold, and D. R. Yáñez-Ruiz. 2012. Effect of bromochloromethane on methane emission, rumen fermentation pattern, milk yield, and fatty acid profile in lactating dairy goats. J. Dairy Sci. 95:2027-2036.

Baldin, M., R. Dresch, J. Souza, D. Fernandes, M. A. S. Gama, K. J. Harvatine, and D. E. Oliveira. 2014. CLA induced milk fat depression reduced dry matter intake and improved energy balance in dairy goats. Small Rumin. Res. 116:44-50.

Beauchemin, K. A. A., M. Kreuzer, F. O’Mara, T. A. A. McAllister, F. O'mara, and T. A. A.
McAllister. 2008. Nutritional management for enteric methane abatement: a review. Aust. J. Exp. Agric. 48:21-27.

Chaucheyras-Durand, F., E. Chevaux, C. Martin, and E. Forano. 2012. Use of Yeast Probiotics in Ruminants: Effects and Mechanisms of Action on Rumen pH, Fibre Degradation, and Microbiota According to the Diet. In: Probiotic in Animals. InTech. Available from: http://www.intechopen.com/books/probiotic-inanimals/use-of-yeast-probiotics-in-ruminantseffects-and-mechanisms-of-action-on-rumen-phfibre-degradation-

Ghazal, S., V. Berthelot, N. C. Friggens, and P. Schmidely. 2012. Influence of a supplement containing conjugated linoleic acid on dairy performance, milk fatty acid composition, and adipose tissue reactivity to lipolytic challenge in mid-lactation goats. J. Dairy Sci. 95:7308-7318.

Giger-Reverdin, S., K. Rigalma, M. Desnoyers, D. Sauvant, and C. Duvaux-Ponter. 2014. Effect of concentrate level on feeding behavior and rumen and blood parameters in dairy goats: Relationships between behavioral and physiological parameters and effect of betweenanimal variability. J. Dairy Sci. 97:4367-4378.

Goetsch, A. L. 2016. Invited Review: Current areas of research of feeding practices for lactating goats. Prof. Anim. Sci. 32:725-735.

Goetsch, A. L. 2019. Recent research of feeding practices and the nutrition of lactating dairy goats. J. Appl. Anim. Res. 47:103-114.

Goetsch, A. L., S. S. Zeng, and T. A. Gipson. 2011. Factors affecting goat milk production and quality. Small Rumin. Res. 101:55-63.

Harfoot, C. G., and G. P. Hazlewood. 1988. Lipid metabolism in the rumen. In: P. N. Hobson and C. S. Stewart, editors. The Rumen Microbial Ecosystem. Springer Netherlands, Netherlands. p. 382-426.

Kholif, A. E., M. M. Abdo, U. Y. Anele, M. ElSayed, and T. A. Morsy. 2017. Saccharomyces cerevisiae does not work synergistically with exogenous enzymes to enhance feed utilization, ruminal fermentation and lactational performance of Nubian goats. Livest. Sci. 206:17-23.

Kholif, A. E., T. A. Morsy, G. A. Gouda, U.Y. Anele, and M.L. Galyean, 2016. Effect of feeding diets with processed Moringa oleifera meal as protein source in lactating Anglo-Nubian goats. Anim. Feed Sci. Technol. 217:45-55.

Kholif, A. E., G. A. Gouda, T. A. Morsy, A. Z. M. Salem, S. Lopez, and A. M. Kholif. 2015. Moringa oleifera leaf meal as a protein source in lactating goat's diets: Feed intake, digestibility, ruminal fermentation, milk yield and composition, and its fatty acids profile. Small Rumin. Res. 129:129-137.

Kholif, A. E., G. A. Gouda, O. A. Olafadehan, and M. M. Abdo. 2018. Effects of replacement of Moringa oleifera for berseem clover in the diets 
of Nubian goats on feed utilisation, and milk yield, composition and fatty acid profile. animal. 12:964-972.

Kholif, A. E., T. A. Morsy, A. M. Abd El Tawab, U. Y. Anele, and M. L. Galyean. 2016. Effect of supplementing diets of Anglo-Nubian goats with soybean and flaxseed oils on lactational performance. J. Agric. Food Chem. 64:61636170.

Li, F., Z. Li, S. Li, J. d. Ferguson, Y. Cao, J. Yao, F. Sun, X. Wang, and T. Yang. 2014. Effect of dietary physically effective fiber on ruminal fermentation and the fatty acid profile of milk in dairy goats. J. Dairy Sci. 97:2281-2290.

Lock, A. L., M. Rovai, T. A. Gipson, M. J. de Veth, and D. E. Bauman. 2008. A Conjugated Linoleic Acid Supplement Containing Trans-10, Cis-12 Conjugated Linoleic Acid Reduces Milk Fat Synthesis in Lactating Goats. J. Dairy Sci. 91:3291-3299.

Mamuad, L. L., Sung Sill Lee, and Sang Suk Lee. 2019. Recent insight and future techniques to enhance rumen fermentation in dairy goats. Asian-Australasian J. Anim. Sci. 32:1321-1330.

Maragkoudakis, P. A., K. C. Mountzouris, C. Rosu, G. Zoumpopoulou, K. Papadimitriou, E. Dalaka, A. Hadjipetrou, G. Theofanous, G. P. Strozzi, N. Carlini, G. Zervas, and E. Tsakalidou. 2010. Feed supplementation of Lactobacillus plantarum PCA 236 modulates gut microbiota and milk fatty acid composition in dairy goats - a preliminary study. Int. J. Food Microbiol. 141:S109-S116.

Miri, V. H., A. K. Tyagi, S. H. Ebrahimi, and M. Mohini. 2013. Effect of cumin (Cuminum cyminum) seed extract on milk fatty acid profile and methane emission in lactating goat. Small Rumin. Res. 113:66-72.

Morsy, T. A., A. E. Kholif, O. H. Matloup, A. Abu Elella, U. Y. Anele, and J. S. Caton. 2018. Mustard and cumin seeds improve feed utilisation, milk production and milk fatty acids of Damascus goats. J. Dairy Res. 85:142-151.

Paraskevakis, N. 2015. Effects of dietary dried Greek Oregano (Origanum vulgare ssp. hirtum) supplementation on blood and milk enzymatic antioxidant indices, on milk total antioxidant capacity and on productivity in goats. Anim. Feed Sci. Technol. 209:90-97.

Puchala, R., G. Animut, A. K. Patra, G. D. Detweiler,
J. E. Wells, V. H. Varel, T. Sahlu, and A. L. Goetsch. 2012a. Effects of different fresh-cut forages and their hays on feed intake, digestibility, heat production, and ruminal methane emission by Boer $\times$ Spanish goats1. J. Anim. Sci. 90:2754-2762.

Puchala, R., G. Animut, A. K. Patra, G. D. Detweiler, J. E. Wells, V. H. Varel, T. Sahlu, and A. L. Goetsch. 2012b. Methane emissions by goats consuming Sericea lespedeza at different feeding frequencies. Anim. Feed Sci. Technol. 175:7684.

Razzaghi, A., A. A. Naserian, R. Valizadeh, S. H. Ebrahimi, B. Khorrami, M. Malekkhahi, and R. Khiaosa-ard. 2015a. Pomegranate seed pulp, pistachio hulls, and tomato pomace as replacement of wheat bran increased milk conjugated linoleic acid concentrations without adverse effects on ruminal fermentation and performance of Saanen dairy goats. Anim. Feed Sci. Technol. 210:46-55.

Razzaghi, A., R. Valizadeh, A. A. Naserian, M. Danesh Mesgaran, and L. Rashidi. 2015b. Effects of sucrose and sunflower oil addition to diet of Saanen dairy goats on performance and milk fatty acid profile. Livest. Sci. 173:14-23.

Serment, A., P. Schmidely, S. Giger-Reverdin, P. Chapoutot, and D. Sauvant. 2011. Effects of the percentage of concentrate on rumen fermentation, nutrient digestibility, plasma metabolites, and milk composition in mid-lactation goats. J. Dairy Sci. 94:3960-3972.

Sharifi, M., M. Bashtani, A. A. Naserian, and H. Farhangfar. 2015. The effect of feeding low quality date palm (Phoenix dactylifera L.) on the performance, antioxidant status and ruminal fermentation of mid-lactating Saanen dairy goats. Small Rumin. Res. 130:95-100.

Shingfield, K. J., J. Rouel, and Y. Chilliard. 2008. Effect of calcium salts of a mixture of conjugated linoleic acids containing trans -10 , cis -12 in the diet on milk fat synthesis in goats. Br. J. Nutr. 101:1006-1019.

Toral, P. G., Y. Chilliard, J. Rouel, H. Leskinen, K. J. Shingfield, and L. Bernard. 2015. Comparison of the nutritional regulation of milk fat secretion and composition in cows and goats. J. Dairy Sci. 98:7277-7297. 